\title{
DIE TROUE GOD IS MY BESKERMER: PSALM 59
}

W VOSLOO

\begin{abstract}
The faithful God is my Protector: Psalm 59

The psalm consists of eight strophes, spread over three main sections, that is, verses $2-5 a, 5 b-11$ and $12-18$. The last two main sections are parallel, yet in such a way that strong contrasts are emphasized in order to articulate the message, the main thrust being that the Lord is the faithful Protector, the One who is in control of the whole earth and in whom the believer can trust.
\end{abstract}

In sy kommentaar op die Psalms merk W O E Oesterley" op: "The structure of the psalm is curious." Hy is verder van mening dat dit drie verskillende en onderling uiteenlopende stelsels van strofiese rangskikking openbaar, "none which yields that metrical symmetry which is indispensable for true strophic organization".

W G Scroggie") meen weer "In structure the Psalm is highly artificial." Hy deel dit in twee hoofdele met vers 10 (wat deels in vers 18 herhaal word) as die einde van die eerste deel. Verder meen hy dat die musikale aanduiding "sela" aan die einde van verse 6 en 14 hierdie dele in twee strofes elk verdeel. Die twee hoofdele vertoon ooreenkomste, maar bevat ook eiesoortige kenmerke. Alhoewel Scroggie se indeling aantreklik lyk, lewer dit tog probleme: Hy neem vers 10 as die einde van sy eerste hoofdeel en vers 18 as die einde van sy tweede hoofdeel. Tog bevat vers 18 die begindeel van vers 11 wat in ieder geval baie nou aansluit by vers 10 , eerder as by vers 12 . Vers 18 moet dus gesien word as die herhaling van verse $10-11$. Indien die twee hoofdele parallel is aan mekaar soos hy sê, dan is dit voorts ook moeilik om verse $2-4$ in hierdie skema in te pas.

Ook $\mathrm{H}-\mathrm{J}$ Kraus $^{31}$ het probleme met die indeling en ten opsigte van die herhalings sê hy: "Es fehlt immer noch an einer zureichenden Erklärung, wie diese Varianten ... zu verstehen sind."

'n Verdere ondersoek na die samestelling van Psalm 59, maar dan vanuit 'n ander gesigshoek, blyk dus tog noodsaaklik te wees.

\section{Teksafbakening en hoofdele}

Vers 1 is ' $n$ sekondère interpretasie wat die psalm aan die gebeure van 1 
Samuel 19:11-17 koppel. Dis egter onwaarskynlik dat die psalm histories verband hou met Saul se vervolging van Dawid, aangesien Saul se soldate sekerlik nie vergelyk kan word met honde wat elke aand terugkeer en deur die stad rondsluip nie (7 en 15). Nog minder sou die beskuldigings en oordele van verse $12-14$ op Saul-hulle van toepassing gemaak kan word. Per slot van sake het Saul nie ' $n$ woordestryd gevoer nie, maar wel 'n fisies vervolging. Dit moet dus as 'n latere opskrif beskou word.

Die versoek in vers 2 dat God l'êlohāj die bidder sal beskerm (t'sāgbenin, word op 'n bevestigende wyse in vers 18 herhaal, wanneer daar gesê word, "want God ('êlohîm) is my beskerming (miśgabi)". [Afr.: "want $U$ is my veilige vesting".] Daarmee word die hele psalm omraam en as ' $n$ eenheid saamgebind. Daarbenewens is daar verskeie vorms van interne kohesie, byvoorbeeld deur die herhaling van vers 7 (as 15) en vers 10 (byna woordeliks as 18 ).

* Die eerste hoofdeel is verse $2-5 a$, bestaande uit smeekbede, klag en onskuldbetuiging.

* Die tweede hoofdeel is verse $5 b-11$. Vers $5 b$ begin met ' $n$ wekroep ontleen aan die Kanaänitiese kultus en verse $10-11$ is ' $n$ slotrefrein wat grotendeels weer in vers 18 herhaal word. Dit bevat 'n pleidooi, 'n klag en ' $n$ vertrouensuitspraak.

* Die res van die psalm, verse $12-18$, vorm die derde hoofdeel. Dit bestaan uit 'n oordeelsgebed, klag, vertroue, lof en selfs ' $n$ belydenis.

Skematies kan dit soos volg voorgestel word:
A (2-5a): Smeekbede klag/onskuldbetuiging
B (5b-11): Pleidooi klag/vertroue vertrouensuitspraak
C (12-18): Oordeelsgebed/
vertroue $\mathrm{klag} / \mathrm{vertroue} / \mathrm{lof}$
lof/belydenis

\section{Teksvasstelling}

Die teks van Biblia Hebraica Stuttgartensia (1967/77) word gebruik, maar met die volgende aanpassings:

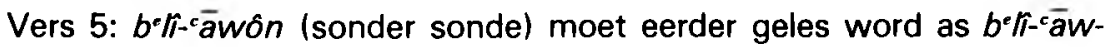


onî (sonder dat ek gesondig het) na aanleiding van die voorafgaande reëlhelfte en die daaropvolgende waw.

Vers 10: ${ }^{c} u z \delta$ (sy sterkte) is onhoudbaar in die sin en moet saam met die LXX en Targum verander word na ${ }^{c}$ uzi (my sterkte).

Vers 11: By hasdiw (3de persoon) moet $\mathrm{Q}$ eerder gevolg word asof dit hasdi (1ste persoon) is.

Vers 16: jeniwûn moet gewysig word na die korrekte vorm jenû́ûn.

\section{Literatuursoort}

Die psalm word meestal as ' $n$ klaag- en bedelied van die enkeling beskou, maar is tog nie 'n suiwer klaaglied of smeekbede nie. Dit bevat smeekbedes, klag, onskuldbetuiging, oordeelsbedes, vertrouensuitsprake, lof en belydenis. Hierdie verskillende stemminge word deurgaans afgewissel sodat elke hoofdeel in ' $n$ mineurtoon begin, maar teen die einde in ' $n$ majeurtoon oorloop. Die laaste hoofdeel is egter veel meer deurspek van 'n positiewe stemming deurdat vertroue, lof en belydenis oorheers. Alhoewel dit grotendeels op die enkeling betrekking het, dui die volkeremotief in verse 6 en 9 op kollektiewe trekke.

\section{Metrum}

Die psalm het geen vaste metrum nie: $3+3$ is oorheersend in die psalm, maar $4+3$ kom in vers 9 voor, $4+4$ in verse $12-13$ a en $2+2+2$ in verse $7,14 \mathrm{~b}$ en 15 . Sowel vers 8 as vers 18 het ook 'n gedeelte van ' $n$ reël van 2 mate elk.

\section{Subperikope: Afbakening, vertaling en verklaring}

(Die vertaling probeer nie om idiomaties te wees nie, maar eerder om waar moontlik so na as moontlik aan die letterlike te bly ter wille van die verklaring daarvan.)

\section{Hoofdeel A: DIE NOODKREET}

\section{1 'n Smeekbede: "Red my ..."}

Verse 2 en 3 word aan mekaar gekoppel deur die herhaalde "red my!" (hassîleni) en die parallelle opbou in chiastiese vorm: 
2. Red my van my vyande, o my God; van my teenstanders beskerm $U$ my!

3. Red my van hulle wat kwaad doen; van bloeddorstiges help $U$ my!

Hierdie subperikoop is die aanroeping waarin by God om hulp gepleit word. Die bidder se vyande word met vier woorde omskryf wat 'n stygende lyn volg met "bloeddorstiges" (dus: "moordenaars") as die klimaks. Hiervolgens kan die nood van die bidder dalk wees dat sekere mense hom om die lewe wil bring. Die woord wat met "beskerm" vertaal is, beteken letterlik "om op 'n hoë plek te bring" of "om agter hoë mure te beskerm". Dit hou dus verband met "hoog wees", "ontoeganklik wees", "'n veilige vesting" en word as "beskerming" of "vesting" ook in verse 10, 17 en 18 aangetref. Dit vervul sonder twyfel die funksie van 'n "Leitwort" in die psalm.

\section{2 'n Klag en onskuldbetuiging: "Sterkes val my aan ..."}

Verse 4-5a word ingelui met 'n redegewende "want" (kn), gevolg deur die grond vir die hulpgeroep, te wete dreiging sonder oorsaak:

4. Want let op! Hulle lê en wag in 'n hinderlaag vir my, sterkes val my aan.

Sonder dat ek oortree of gesondig het,

o Here,

5a. sonder dat ek verkeerd gedoen het, bestorm hulle my en is gereed vir die aanval.

Die klag en betuiging van onskuld is met mekaar deurweef en verskyn nie in die vorm van aparte dele nie. Die hinderlaag moet metafories verstaan word en die onskuldbetuiging moet nie verwar word met sondeloosheid nie. Die bidder sê daarmee dat hy niks teenoor sy vyande gedoen het wat hulle die reg gee om sy lewe te neem nie. Omdat hy dus onskuldig staan teenoor hulle, kan hy hom op die beskerming van die Here beroep. Die onskuldige vervolging van die vrome bied grond vir die vertroue dat God wel sal verhoor. ( $\mathrm{Vgl}$ in dié verband bv Pss 35:7,19; 69:5; 109:3; 119:161.) Die naam van die Here op wie die bidder 'n beroep doen, staan nie aan die begin van die klag nie, maar in die middel. Deur die naam as't ware so te omkring met die omstandighede waaronder hy verkeer, wil die bidder die dringendheid van sy nood beklemtoon.

\section{Hoofdeel B: DIE HULPKREET}

\section{3 'n Pleidooi om hulp: "Ontwaak, Here ..."}




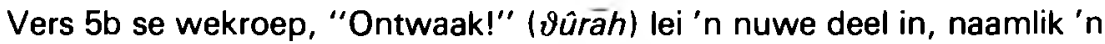
pleidooi dat die Here moet ingryp. Dit vind 'n weerklank in vers $6 b$ se wekroep "Word wakker!" (haqiśah). Vers 6b en 6c staan weer parallel aan mekaar, opvallend verbind deur die herhaling van "al" ( $k a /$, soos vers $5 b$ ook ' $n$ parallelle opbou het. Daardeur omkring die twee parallelle wekroepe die sentrale sin, naamlik die volle benaming van die Here:

5b. Ontwaak om my te help -

kyk tog [wat hulle doen]l

6. $U$ is tog die Here God, die Almagtige, die God van Israel. Word wakker om al die nasies te oordeel moenie al die verraaiers genade betoon nie!

Sela

Albei wekroepe is ontleen aan die Kanaänitiese kultusgroep waardeur die gestorwe natuurgod weer tot lewe gewek word by die aanbreek van die lente. Die wekroepe word egter gestroop van alle heidense ondertone deur die volle naam van die God van Israel in die sentrum van die parallelle struktuur te plaas. Daardeur wil hierdie subperikoop al die aandag op die Here, die magtige God van Israel vestig: Nie die natuurgod is die helper nie, maar die Here. Die wekroep is metafories bedoel omdat dit wil voorkom asof die Here nie ag slaan op die pleidooi van die bidder nie. (Vgl Ps 78:65; 44:24.)

Die letterlike weergawe van "verraaiers" is eintlik "trouelose boosdoeners", maar omdat dit parallel staan teenoor "nasies" is dit miskien beter om dit met "verraaiers" te vertaal. Ook in die Qumran-tekste word bogedîm gebruik as aanduiding van die afvalliges of verraaiers. Die onregverdige vervolging wat hy moet verduur, laat die bidder dink aan die onheil en onreg in die breë, sodat sy pleidooi oorgaan in 'n smeking dat regspraak beoefen moet word oor "die nasies" en die "trouelose boosdoeners" (verraaiers) wat met hulle saamspan. Op hierdie wyse word die onreg teen die enkeling aanleiding vir ' $n$ klag oor die onreg teen die gemeenskap, want eintlik is die enkeling aangewese op die gemeenskap.

\section{4 'n Klag gewortel in vertroue: "Hulle kom terug, maar U ..."}

Vers 7 lei 'n nuwe subperikoop in met die metafoor van die stadshonde. Hierdie metafoor loop oor na vers 8 , waar die metafoor reeds so met die werklikheid verweef is dat dit moeilik is om te bepaal of daar nog metafories vertaal moet word en of die saak reeds gestel is. Wanneer die deel egter met sy parallel in verse 15 en 16 vergelyk word, wil dit 
voorkom asof die metaforiese vertaling verkies moet word. Daarteenoor lei die kî waarmee vers $8 \mathrm{c}$ begin die direkte rede in, waarmee daar reeds oorgegaan is na 'n nie-metaforiese spreekwyse. Vers 9 wil die optrede van die Here kontrasteer met dié van die vyande van vers $7-8$ en word ingelei met ' $n$ regressiewe waw. Daarom hoort dit by die voorafgaande twee verse:

7. Hulle kom terug in die aand, hulle grom soos honde, hulle dwaal deur die stad.

8. Kyk! Kwyl staan op hulle mond, hulle wys hulle tande (terwyl hulle dink): Wie sal dit hoor?

9. Maar $U$, o Here, lag vir hulle, $U$ spot met al die nasies.

Die stadshonde het snags rondgedwaal om prooi te soek. Met hierdie beeld word sowel die aanstootlikheid as die wraaklus van die vyande uitgebeeld. Die res van die beeld wil die vyandigheid van die honde, of eintlik die vyandige uitsprake van die vyande uitbeeld. (Letterlik staan daar in vers 8, "Kyk hulle laat dit voortvloei uit hulle mond, swaarde is op hulle lippe!") Wat hulle sê, is net so gevaarlik soos oorlogswapens ("swaarde"). Dat die klem hier op die afbrekende woorde val, blyk uit die vraag, "Wie sal dit hoor?", die parallel, "lag vir hulle" en "spot", asook die beskuldigings in vers 13. Hulle tree op asof daar niemand is wat kennis dra van hulle woorde nie, ook nie God nie. Tog is daar 'n keersy, die kontras: "Maar U, o Here ...". Die vyande het geen rekening gehou met die Here nie. Hy sal laat reg geskied teenoor hulle onreg.

Waar daar in verse $5 b-6$ gebruik gemaak is van ' $n$ Kanaänitiese kultusroep, word hier weer gebruik gemaak van 'n uitspraak eie aan die Jerusalemse kultus, 'n tipiese Sionstradisie, naamlik dat die Here sal lag en spot wanneer die nasies (volkeremotief) 'n aanslag op die stad maak (vgl Ps 2:4). In hierdie geval vind ons egter die merkwaardige dat aansprake eie aan die Sionstradisie nou op 'n enkeling van toepassing gemaak word. Net so min as wat die nasies die stad van God sal verower, net so min sal die vyande slaag in hulle aanvalle op die bidder omdat hy sy vertroue in die Here stel, net soos die stad op Hom vertrou.

\section{5 'n Vertrouensuitspraak: "My Sterkte ..."}

Verse $10-11$ is 'n vertrouensuitspraak wat hierdie hoofdeel afsluit. Dit funksioneer as ' $n$ refrein, aangesien dit aan die einde van die volgende hoofdeel (in ietwat gewysigde vorm) herhaal word en so die psalm as geheel ook afsluit. Die parallelle struktuur van die twee verse beklemtoon dat hulle 'n eenheid vorm: 
10. My Sterkte, op $U$ wag ek, want God is my beskerming.

11. My troue God kom my tegemoet, God laat my neersien op my vyande.

Teenoor die "sterkes" (4) wat die bidder bedreig, is God sy "Sterkte" op wie hy hoop. Nogtans waag hy dit nie om God tot optrede te dwing nie, maar "wag" op Hom, waaruit sy vertroue soveel duideliker spreek. Die oorspronklike smeekbede dat God hom moet beskerm (2), word nou deur gebruikmaking van dieselfde stam $(s g b)$ omskep in ' $n$ vertrouensuiting, "my beskerming" (wat ook vertaal kan word met "vesting").

Vers 11 brei verder uit op hierdie vertroue. Die woord "troue" (hêêêd) wil 'n bepaalde verbintenis omskryf en elemente soos liefde, medelye, guns, trou en verbondenheid is almal deel van daardie verhouding. Met ander woorde, die bidder se vertroue dat God hom tot hulp sal kom ("kom my tegemoet"), is gegrond op die besondere verhouding wat daar tussen hom en God bestaan. Daarop vestig hy sy hoop. Die uitdrukking "neersien" (letterlik: "laat sien op") hou verband met die "beskerming" (vesting), want hy wat veilig in die beskerming van ' $n$ vesting sit, kyk eintlik neer op die vyande wat dit omring. Aan die ander kant wil dit 'n kontras vorm met die "hoogmoed" van die vyande (13) wat eers op hom neergesien het, maar nou na hom toe moet opkyk.

\section{Hoofdeөl C: DIE LOFKREET}

\section{6 'n Oordeelsgebed in vertroue: "Vernietig hulle, Here ..."}

Die volgende gedeelte is ' $n$ oordeelsgebed wat gewortel is in die vertroue van God se heerskappy. Dit word deur vers 12 ingelui met die pleitrede: "Moenie hulle doodmaak nie sodat ... nie vergeet nie" ('al-tahargem pên-jisk hâ). Vers 14 sê weer net die teenoorgestelde, naamlik "Vernietig hulle ... dan sal hulle weet" (kalleh ... wejjedeca). Daarmee word verse $12-14$ as 'n subperikoop afgebaken:

12. Moenie hulle [dadelik] doodmaak nie sodat my volk nie vergeet nie, laat hulle waggel deur U krag en werp hulle neer, Here ons Skild!

13. Weens die sonde van hulle mond, die woorde van hulle lippe sal hulle gevang word in hulle hoogmoed, ja, weens die vervloeking en leuens wat hulle vertel.

14. Vernietig [hulle] in toorn, vernietig dat hulle nie meer bestaan nie. 
Dan sal hulle weet: God heers in Jakob en tot aan die einde van die aarde.

Alhoewel die teks letterlik lees: "Moenie hulle doodmaak nie ...", is dit uit die teksverband duidelik dat die woord "dadelik" ingelees moet word. Die bedoeling is dat die vyande eers die mag van die Here moet beleef en so vir die volk 'n getuie word van sy krag. "Waggel" dui daarop dat hulle besig is om in te gee onder die aanslag van die krag van die Here alvorens Hy hulle heeltemal vernietig. "Skild" is hier 'n metafoor vir God se beskerming. In vers 13 volg 'n samevatting van die oortredings van die vyande, waaruit blyk dat aanmatigende gedagtes en aanstootlike woorde net sulke afskuwelike sondes is as verkeerde dade. Hoogmoed is dié sonde wat die Ou Testament van die begin af veroordeel as 'n opstand teen God. Vervloeking hou verband met die opvatting dat woorde op magiese wyse werklik in vervulling sal gaan. Die "leuens" verwys na valse beskuldigings waarmee die vyande hoop om die bidder vas te trek.

Alhoewel "hulle" nie in die teks staan nie, veronderstel die konteks dit. Die herhaalde pleidooi "vernietig ...", dui op beklemtoning. Hierdie vers staan in kontras met vers 12; In vers 12 was die pleidooi dat die vyande nie onmiddellik doodgemaak moet word nie om te verhoed dat die volk "vergeet" dat die Here 'n beskerming is vir diegene wat op Hom vertrou en verantwoording eis van diegene wat oortree. In vers 14 is die pleidooi dat die Here hulle nou tog sal vernietig sodat die volk sal "weet" dat God die elntlike heerser is in sy volk. As mense dalk sou dink dat hulle maar kan maak soos hulle wil, moet God se optrede teenoor die kwaaddoeners hulle tot besinning bring en tot die erkenning dat God nie die beheer uit sy hande laat gaan het nie. Vir diegene wat onreg moet verduur, is dit ' $n$ troos en bron van hoop.

Die uitdrukking "God heers in Jakob" is eie aan die Jerusalemse kultus en 'n beklemtoning dat die Here in die geloofsgemeenskap ("Jakob" verwys hier na 'n godsdienstige entiteit) as Koning regeer en as Regter optree. Tog is sy jurisdiksie nie beperk tot die geloofsgemeenskap alleen nie, maar strek oor die hele aarde. Hierdie vers verraai so die geheim van die bidder se vertrove midde-in sy nood.

Hierdie subperikoop vorm die teenhanger van subperikoop 3 $(5 b-6)$. Albei is opgebou uit twee verbandhoudende gedeeltes wat die sentrale saak omkring. In verse $5 b-6$, die twee wekroepe wat die naam van die Here omkring en beklemtoon; en in verse 12-14, die twee oordeelsbedes wat die sondes van die vyande omkring en beklemtoon. Op hierdie wyse word die mag van die Here gestel teenoor die boosheid van die vyande. 
5.7 'n Klag, vertroue en lof: "Húlle kom terug, maar ék sing ..."

Vers 15 is ' $n$ herhaling van vers 7 en die metafoor van die stadshonde word in vers 16 voortgesit. Die waw aan die begin dui op beklemtoning. Vers $17 \mathrm{a}$ is deur kontrastering direk aan vers 16 gekoppel, duidelik aangedui deur die beklemtoning van "Hulle" (hemmah) en "Maar ek" (wa'anî) aan die begin van elke vers. Vers $17 \mathrm{~b}$ word weer aan die voorafgaande verbind deur die redegewende "want" $(k \hat{i})$ :

15. Húlle kom terug in die aand, hulle grom soos honde, hulle dwaal deur die stad.

16. Húlle swerf rond op soek na prooi en as hulle nie versadig word nie, tjank hulle.

17. Maar ék sing van $U$ sterkte en jubel in die oggend oor $U$ trou, want $U$ is ' $n$ beskerming vir my en 'n toevlug op die dag van my benoudheid.

Hierdie subperikoop vorm 'n parallel met subperikoop 4 (7-9). Dáár word die optrede van die Here teenoor dié van die vyande gestel. Hiér word die optrede van die bidder weer vergelyk met dié van die vyande, waaruit sy vertroue duidelik blyk. In hulle vervolgingswaan is die vyande soos honde wat gedurig terugkeer en loop en soek na prooi. Die bidder, egter, het geen vrese nie en kan sing en bly wees oor die beskerming wat hy ervaar in God se teenwoordigheid. Die kontras word nog skerper toegelig deur die optrede van die vyande aan die "aand" te verbind en dié van die bidder aan die "oggend". Die aand en die nag word dikwels metafories gebruik vir bedreiging of onheil (vgl bv Jes 17:14 en Ps 30:6). Soortgelyk het die oggend die funksie van vreugde en hoop (vgl bv Ki $3: 21-23$; Ps $90: 14 ; 92: 3 ; 143: 8$ ). Wanneer God die gelowige red uit sy "benoudheid", antwoord hy met lof en jubeling oor die "trou" (hêêed, vgl 11) en "beskerming" (miśgab, vgl 2 en 10) wat hy ervaar. Met "toevlug" (manôs) word die beeld van 'n vesting (miśgab) waarheen 'n bedreigde persoon vir beskerming kan vlug weer eens beklemtoon.

\section{8 'n Lofuiting en belydenis: "My Sterkte!"}

Vers 18 vorm die afsluiting van hierdie deel en die psalm:

18. My Sterkte, vir $U$ wil ek psalmsing, want God is $m y$ beskerming, my troue God! 
Vers 18 is die teenhanger van verse $9-10$, want al is dit net 'n gedeeltelike herhaling, is dit tog drie sleutelwoorde wat herhaal word. In verse 9-10 "wag" die bidder nog op die redding en dat God hom sal kom help om uit 'n veilige vesting op sy vyande "neer te sien". In vers 18 loof hy God asof hy reeds uit sy benoudheid verlos is. Die psalm het begin met 'n bede dat God die bidder sal beskerm (t'sagbenî) en eindig nou met die belydenis dat God inderdaad sy beskerming of veilige vesting (miśgabbi) is. Waar die woorde "my troue God" in vers 11 'n klank van hoop is, word dit in vers 18 ' $n$ uitroep van lof en belydenis, dramaties beklemtoon deur die plotselinge einde sonder verdere toeligting soos in vers 10.

\section{Struktuur}

Die struktuur van die psalm kan nou soos volg skematies voorgestel word:

\section{DIE NOODKREET}

1. Red my ...

2. Sterkes val my aan ...

\section{DIE HULPKREET}

3. Ontwaak, Here ..

4. Hulle kom terug, maar $\mathrm{U}$...

5. My Sterkte ...

\section{DIE LOFKREET}

6. Vernietig hulle, Here ...

7. Húlle kom terug, maar ék sing ...

8. My Sterkte!

Die parallelle konstruksie van die tweede en derde hoofdeel blyk reeds uit hierdie diagram, maar die volgende skematiese weergawe van die inhoud van elke subperikoop maak dit nog duideliker:

\section{DIE HULPKREET}

3. Ontwaak, Here

:5b Ontwaak

:6a $\quad \mathrm{U}$ is die Here

:6b Word wakker

4. Hulle kom terug

$: 7 \quad \ldots$ soos honde

:8 Hulle ...

:9 Maar U ...

5. My Sterkte

:10 My Sterkte ... beskerming

:11 My troue God ... neersien

\section{DIE LOFKREET}

6. Vernietig hulle, Here

:12 Moenie doodmaak nie

$: 13$ Hulle sondes

:14 Vernietig hulle

7. Húlle kom terug

$: 15 \ldots$ soos honde

:16 Hülle...

:17 Maar ék ..., want ...

8. My Sterkte

:18a My Sterkte ... beskerming

:18b My troue God! 
Die parallelle struktuur van die psalm is egter eerder bedoel om te kontrasteer as om te herhaal. Die volgende geld as voorbeelde: die nood en die redding; die mag van die Here en die boosheid van die vyande; die effek van 'n geleidelike afbreek en dié van 'n totale vernietiging; die vyande se optrede en God se reaksie; die vyande (honde) se soek na kos en hulle onvermoë om dit te kry; in die aand en in die oggend; die vyand as die "sterkes" en die Here as die Sterke; die vyand se wraaksug en die bidder se lof; wag op God en sing tot God. Deur so telkens op die teenstelling te wys, word die boodskap duideliker in fokus gebring.

\section{Die boodskap}

Die hoofgedagte van hierdie psalm is die troue beskerming wat die Here bied vir diegene wat op Hom vertrou. $\mathrm{Hy}$ is in beheer van sake omdat $\mathrm{Hy}$ die heerser oor die hele wêreld is. Al lyk omstandighede nog so dreigend, bied $\mathrm{Hy}$ beskerming aan diegene wat by Hom skuil. Dan verander ' $n$ noodkreet tot ' $n$ loflied en ' $n$ smeekbede tot ' $n$ belydenis.

Daar is geen aanduiding in die psalm dat die bidder se lof en belydenis die resultaat was van sy redding nie. Veeleer kry ' $n$ mens die indruk dat dit voór die redding plaasgevind het. Daarmee word iets belangriks gesê: Lof is nie net die uiting van dankbaarheid nie, maar juis die kenmerk van geloof. Hy wat kan loof en bely voordat hy ontvang het, openbaar ' $n$ ware vertroue; en vertroue is die basis van geloof.

Die psalm verwys na 'n hele aantal sake op grond waarvan die gelowige sy vertroue op God kan bou: Wanneer hy onverdiende wraaksug en onreg moet verduur (4-5b); die mag van die Here (9); die getuieniskrag van God se ingrype $(12,14)$; sy besondere verhouding met die Here $(9,11)$; die Here se heerskappy in geloofsgemeenskap en oor die hele wêreld (14).

Ten slotte word beklemtoon dat redding lei tot lof aan God en die belydenis dat $\mathrm{Hy}$ betroubaar is, ' $\mathrm{n}$ God wat die gelowige nie in die steek laat nie.

\section{Notas}

1. WO E Oesterley, The Psalms, London 1962, 294.

2. W G Scroggie, The Psalms II, London 1965, 55.

3. H J Kraus, Psalmen I, Neukirchen-Vluyn 1960, 421.

\section{Literatuurlys}

A A Anderson, The book of Psalms I, London 1972.

G J Botterweck \& H Ringgren (Hrsg), Theologisches Wörterbuch zum Alten Testament I, Stuttgart 1970/73. 
E Jenni \& C Westermann, Theologisches Handwörterbuch zum Alten Testament I, München 1971.

E Jenni \& C Westermann, Theologisches Handwörterbuch zum Alten Testament II, München 1976.

H-J Kraus, Psalmen I, Neukirchen 1960.

E A Leslie, The Psalms, Nashville 1949.

W O E Oesterley, The Psalms, London 1962.

J Ridderbos, De Psalmen II, Kok 1958.

W G Scroggie, The Psalms II, London 1965.

$\mathrm{J}$ van der Ploeg, Psa/men I, Roermond 1973.

N A van Uchelen, Psalmen II, Nijkerk 1977. 